\title{
Review of the Spalart-Allmaras Turbulence Model and its Modifications to Three-Dimensional Supersonic Configurations
}

\author{
$\check{C ̌ e d o m i r ~ K o s t i c ́ ~}^{1)}$
}

\begin{abstract}
The Spalart-Allmaras (SA) model is a turbulence model for modeling different types of turbulent flows, especially in aerodynamics. Until 1992, when it was published by Spalart and Allmaras, there had been modified different terms of the governing equation of this model (prediction, diffusion and destruction). In this literature review, one can go through the details of the governing equation of this model and the role of each term and reasoning behind it. The model is implemented in three-dimensional compressible supersonic flows, and validated for two different configurations: a ballistic missile and a cruciform missile simulations show the ability of the method to snap the interaction between the fuselage vortices and the winglets
\end{abstract}

Key words: aerodynamics, computational fluid dynamics, process modeling, turbulence flow, supersonic flow, computational simulation, projectile aerodynamics.

\section{Notation and symbols}

$T \quad$ - Temperature

F $\quad-$ Force

$V \quad-$ Velocity

$x, y, z$ - Physical Carthesian coordinate axes

$\alpha \quad-$ Angle of attack (degree)

$\gamma \quad$ - Ratio of specific heats

$M, \mu t$ - Laminar, eddy viscosities

$\rho \quad-$ Density

$C A$ - Total axial force coefficient

Caf - Skin friction coefficient

$\mathrm{Cl}$ - Roll moment coefficient

$C_{N} \quad$ - Normal force coefficient

$C p$ - Pressure coefficient

$D$ - Diameter of the fuselage

E - Total energy

$M \quad$ - Mach number

$P \quad$ - Static pressure

$P_{0} \quad$ - Total pressure

RANS - Reynolds-averaged Navier-Stokes equations

\section{Introduction}

G OMPUTATION Fluid Dynamics (CFD) has got an Tincreasingly significant role in aircraft aerodynamic design. CFD commercial packages, like FLUENT, make performing numerical simulations easier than ever. An easy access to the required tool for doing different types of CFD works can run a simulation successfully; however, the results sometimes do not make any physical sense or can even be totally wrong.

The prediction of flow phenomena such as a boundary layer picture, precisely boundary layer separation or shock boundary layer interaction, depends strongly on the choice of the turbulence model. The renowned models are: Baldwin Lomax, commonly used in industrial missile applications, Degani - Schiff and Deck - Guillen, algebraic models built to calculate attached turbulent boundary layers. They need several modifications to calculate other flow fields.

Two equation models sometimes have to be aware of wall distances, but in same tame can be formulated autonomously of the flow topology and therefore they are more suited to computations of complex geometries. They take physically into account history effects through transport equations.

H.Daniau [1] has illustrated a review of transport equation models capacities and has shown that some models can be difficult to implement in a general way. Boundary wall conditions are not straightforward and can influence stability and correctness of calculations. Numerical problems restrict their general application.

One-equation models give the impression of being a compromise between algebraic and two-equation models. The Spalart-Allmaras model solves directly the transport equation for the vortex viscosity. In this paper, the details of each term of the governing equation are reviewed and different proposed modifications are explained. The last section relies on the numerical aerodynamic calculation of two typical external configurations.

\section{Spalart-Allmaras Governing Equation}

\section{The Basic Equations}

The Spalart-Allmaras model is a one-equation turbulence model that has been developed primarily for aerodynamic flows. This model is a transport equation for eddy viscosity.

\footnotetext{
1) $204^{\text {th }}$ Air Force Brigade RS, Pukovnika Milenka Pavlovića bb, 11273 Batajnica, SERBIA

Correspondence to: Čedomir Kostić; e-mail: cedokostic@gmail.com
} 
In order to develop a closed system of the central equation for the mean motion of a flow, one would determine the distribution of the Reynolds stress.

Generally any transportable scalar quantity, such as eddy viscosity, subject to the conversion laws, is transported according to the following equation, which is the basic equation:

$$
\begin{aligned}
& \frac{D F}{D t}=\frac{\partial F}{\partial t}+(u \cdot \nabla) F= \\
& =\text { Deffusion }+ \text { Production - Destruction }
\end{aligned}
$$

To construct a full model for a turbulent flow, each of diffusion, production and destruction terms should be defined carefully. Defining these terms and making them non-dimensional will result in some additional constants and non-dimensional functions in each term.

The transport equation for the working variable $\tilde{v}$ is given by:

$$
\begin{aligned}
& \frac{\partial \tilde{v}}{\partial t}+\widetilde{u_{j}} \frac{\partial \tilde{v}}{\partial x_{j}}=\underset{\text { Production }}{C_{b 1}} \tilde{S} \tilde{v}+ \\
& +\frac{1}{\sigma}\left[\frac{\partial}{\partial x_{j}}\left((v+\tilde{v}) \frac{\partial \tilde{v}}{\partial x_{j}}\right)+c_{b 2} \frac{\partial \tilde{v}}{\partial x_{j}} \frac{\partial \tilde{v}}{\partial x_{j}}\right]-c_{w 1} f_{w}\left(\frac{\tilde{v}}{d}\right)^{2}
\end{aligned}
$$

The eddy viscosity is defined as:

$$
\mu_{t}=\bar{\rho} \tilde{v} f_{v 1}=\bar{\rho} v_{t}
$$

In the log layer, it can be said that is $\tilde{v}=k y u_{\tau}$, therefore in the buffer layer and the viscous sublayer, too.

The damping function $f_{v_{1}}$ is defined as:

$$
f_{v 1}=\frac{\chi^{3}}{\chi^{3}+c_{v 1}^{3}} \text { where is } \chi=\frac{\tilde{v}}{v}
$$

The vorticity magnitude $S$ is adapted such that $\tilde{S}$ keeps up its log-layer conduct $\left(\tilde{S}=u_{\tau} / k y\right)$ :

$$
\tilde{S}=\sqrt{2 \Omega_{i j} \Omega_{i j}} f_{v 3}+\frac{\tilde{v}}{k^{2} d^{2}} f_{v 2}
$$

where:

$$
\begin{gathered}
\Omega_{i j}=\frac{1}{2}\left(\frac{\partial \tilde{u}_{i}}{\partial x_{j}}-\frac{\partial \tilde{u}_{j}}{\partial x_{j}}\right) \\
f_{v 2}=1-\frac{\chi}{1+\chi f_{v 1}}
\end{gathered}
$$

and

$$
f_{v 3}=1
$$

In order to obtain a faster decaying behavior of destruction in the outer area of the boundary layer, the function $f_{w}$ is used:

$$
f_{w}(g)=g\left(\frac{1+c_{w 3}^{6}}{g^{6}+c_{w 3}^{6}}\right)^{1 / 6}
$$

where:

$$
g=r+c_{w 2}\left(r^{6}-r\right) \text { and } r=\frac{\tilde{v}}{\tilde{S} k^{2} d^{2}}
$$

Here the value $g$ performs as a limiter that prevents large values of $f_{w}$ in the log-layer and decreases in the outer area. The above function is shown in Fig.1.

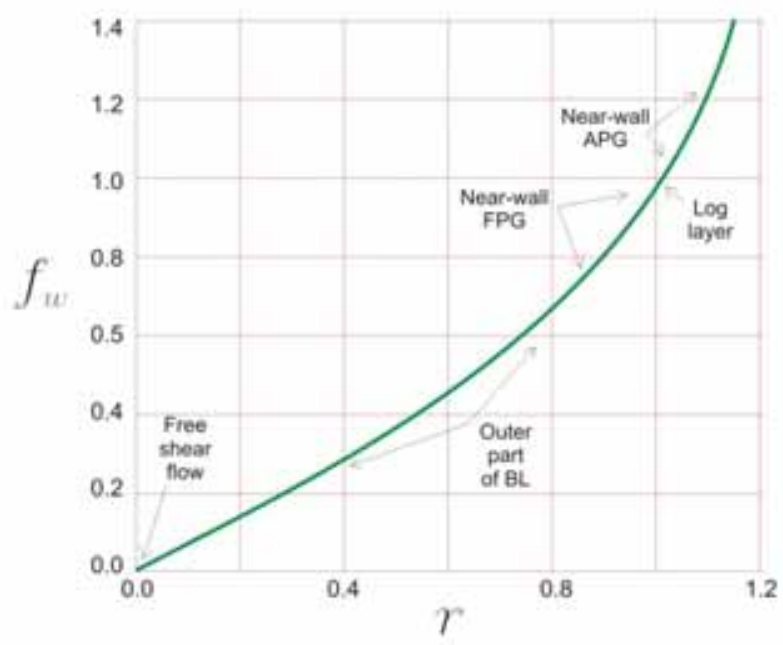

Figure 1. $f_{w}$ function involved in the destruction term [2]

The results are most sensitive to the slope of $f_{w}$ at $r=1$, which is controlled by $c_{w_{3}}$. The step from $g$ to $f_{w}$ works as a limiter that prevents large values of $f_{w}$, which could be problematic for numerical simulations and gives an underserved importance to the fact that $S$ can fade away.

The area $r>1$ is exercised only in advance pressure gradients. The value $f_{w}(0)=0$ is not indispensable, since in free shear flows the destruction term vanishes on account of the $d^{2}$ according to the calibration reasonable values for $c_{w_{2}}=0.3$ and $c_{w_{3}}=2$.

\section{Calibration of the Spalart-Allmaras Model}

In the process of calibration, constants and functions are defined with a help of experimental and numerical results of the type of a flow that has to be modeled.

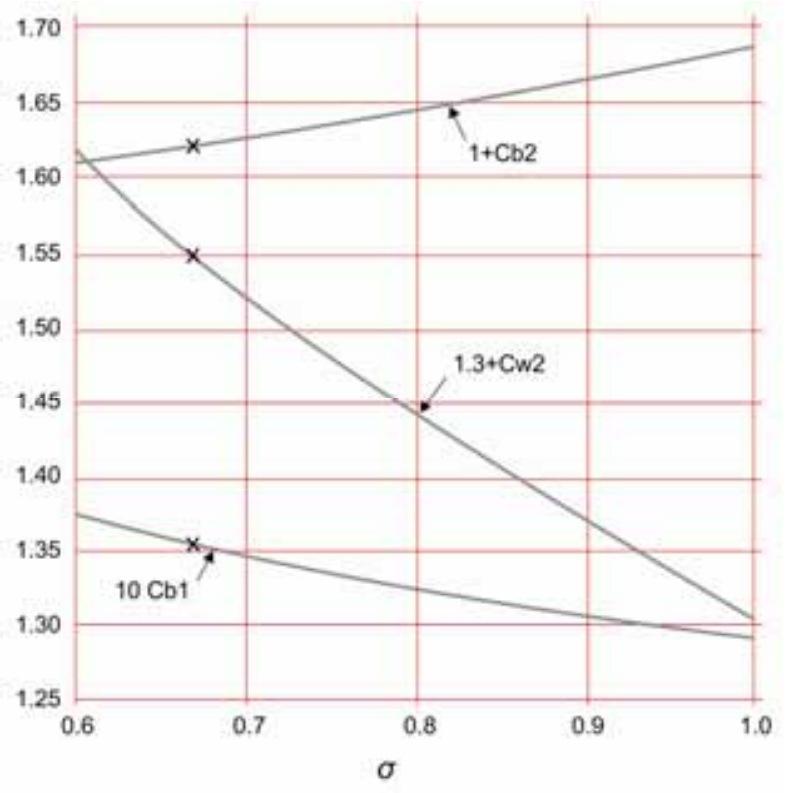

Figure 2. Calibrated model constants [2].

The free shear flow of the model requires correct levels of shear stress in two dimensional mixing layers and wakes. 
Proper values for the peak shear stress were measured to be $0.01(\Delta V)^{2}$ and $0.06(\Delta V)^{2}$ for the mixing layer and the wake respectively, where $\Delta V$ is the peak velocity difference.

This gave two conditions for three free constants $c_{b_{1}}, \sigma$ and $c_{b_{2}}$, and leaves a one-dimensional relation of solutions presented in Fig.2, parameterized by the Prandtl number $\sigma$.

According to the above conclusions in the numerical simulation results, the Spalart-Allmaras suggested values for the constants are given in Table 1.

Table 1. Suggested values for the constants [2 and 3]

\begin{tabular}{|c|c|c|c|c|c|c||}
\hline$c_{b_{1}}$ & $c_{b_{2}}$ & $\sigma$ & $\frac{\left(1+c_{b_{2}}\right)}{\sigma}$ & $c_{v_{1}}$ & $c_{w_{2}}$ & $c_{w_{3}}$ \\
\hline 0.1355 & 0,622 & $\frac{2}{3}$ & $\approx 2.4$ & 7.1 & 0.3 & 2 \\
\hline
\end{tabular}

Finally, the only remained constant and the nondimensional function to be defined is the one in the definition of the destruction term. Spalart andAllmaras argued that in a classical log-layer, with friction velocity and turbulent kinetic energy $k$, the strain rate tensor and eddy viscosity are defined as in equation (5), and that a consideration of the equilibrium between the production, diffusion and the destruction term is possible, provided that the constant $c_{w_{1}}$ in the destruction term is defined as a function of other constants:

$$
c_{w 1}=\frac{c_{b 1}}{k^{2}}+\left(1+c_{b 2}\right) / \sigma
$$

where:

$$
k=0.41
$$

\section{Spalart's Modifications}

Specific tasks showed a poor convergence of the residual turbulence near reattachment. This problem, tag (traced) to $\tilde{S}$, is going negative which distributed $r$ and resulted in blinking. Spalart anticipated the following modification:

$$
\tilde{S}=\tilde{f}_{v 3}(\chi) S+\frac{\tilde{v}}{k^{2} d^{2}} \tilde{f}_{v 2}(\chi)
$$

with:

$$
\begin{aligned}
& \tilde{f}_{v 2}(\chi)=\left(1+\frac{\chi}{c_{v 2}}\right)^{-3} \\
& \tilde{f}_{v 3}(\chi)=\frac{\left(1+\chi f_{v 1}\right)\left(1-\tilde{f}_{v 2}\right)}{c_{v 2}}
\end{aligned}
$$

It can be noticed that $\tilde{S} \geq 0$. In spite of the fact that both $\tilde{v}$ and $S$ are equal to zero, $\tilde{S}$ is still zero. Spalart suggested to take $\max \left(\chi, 10^{-4}\right)$ as a substitute of $\chi$ and $c_{v_{2}}=5$.

The modified $f_{v 2}$ remains along the wall. The function $f_{v 3}$ varies remarkably from 1 in the vicinity of walls.

\section{Spalart-Allmaras Governing Equation}

\section{Integral Form of Governing Equations}

The Navier-Stokes equations are governing ones. In case of turbulent flows, a Reynolds averaged form is used (mass represents conservative variables and represents the main flow contribution. Considering a finite volume $\Omega$, where $\partial \Omega$ is a surface with an exterior normal $\vec{n}$, the Reynoldsaveraged Navier-Stokes equations (or RANS equations) can be transformed into the following form:

$$
\begin{aligned}
& \frac{\partial}{\partial t} \int_{\Omega} \vec{W} d \Omega+\oint_{\partial \Omega}\left\{\overline{\overline{\mathcal{F}}}_{c}[\vec{W}]-\overline{\overline{\mathcal{F}}}_{d}[\vec{W}, \nabla \vec{W}]\right\} \cdot \vec{n} d \Sigma= \\
& =\int_{\Omega} \vec{T}[\vec{W}, \nabla \vec{W}] d \Omega
\end{aligned}
$$

where:

$$
\begin{gathered}
\vec{W}={ }^{t}(\bar{\varrho}, \bar{\varrho} \vec{V}, \varrho E)+{ }^{t}(\underline{\varrho} \tilde{v}) \\
\overline{\mathcal{F}}_{c}={ }^{t}(\varrho \vec{V}, \varrho(\vec{V} \otimes \vec{V})+P \overline{\bar{l}}, \varrho E \vec{V}+P \vec{V})+ \\
+{ }^{t}(\bar{\varrho} \tilde{v} \cdot \vec{V}) \\
\overline{\overline{\mathcal{F}}}_{d}={ }^{t}\left[(0), \bar{\tau}+\overline{\overline{\tau_{R}}}\left(\tilde{\tau}+\bar{\tau}_{R}\right)(0), \bar{\tau}+\overline{\overline{\tau_{R}}},(\bar{\tau}+\overline{\bar{\tau}}) \cdot \vec{V}-\left(\vec{q}+\vec{q}_{t}\right)\right]+ \\
+{ }^{t}\left(\frac{1}{\sigma}(\mu+\bar{\varrho} \tilde{v}) \nabla \tilde{v}\right) \\
\vec{T}={ }^{t}(o)+{ }^{t}\left(c_{b 1} \tilde{S} \bar{\varrho} \tilde{v}+\frac{c_{b 2}}{\sigma} \nabla \bar{\varrho} \tilde{v} \nabla \tilde{v}-\bar{\varrho} c_{w} f_{w}\left(\frac{\tilde{v}}{d}\right)^{2}\right)
\end{gathered}
$$

The above system of RANS equations is stated in an absolute frame. Turbulence contribution is reduced to $\overline{\bar{\tau}}_{R}$ (the Reynolds tensor) and to $\vec{q}_{t}$ (the turbulent heat transfer). The first term of the above equations is zero to remember that the turbulence equation is separated from RANS equations. This maneuver makes the numerical implementation easier and reduces time for computation.

The next step is assuming the air as an ideal gas. The state equation relates the static pressure $P$ to the conservative variables:

$$
P=(\gamma-1)\left(\varrho E \frac{(\varrho \vec{V})^{2}}{2 \varrho}\right)
$$

For a Newtonian fluid, shear stresses and related to mean velocity gradients. Evident turbulent stresses are related to mean velocity gradients. Using the Boussinesq's assumption:

$$
\overline{\bar{\tau}}+\overline{\bar{\tau}}_{R}=\left(\mu+\mu_{t}\right)\left(-\frac{2}{3}(\operatorname{div} \vec{V}) \overline{\bar{l}}+\left(\overline{\overline{\operatorname{grad}}} \vec{V}+{ }^{t} \overline{\overline{\operatorname{grad}}} \vec{V}\right)\right)
$$

The influence of the laminar viscosity on temperature Spalart-Allmaras - brings through:

$$
\mu(T)=\mu_{0}\left(\frac{T}{T_{0}}\right)^{3 / 2} \cdot \frac{T_{0}+110.4}{T+110.4}
$$

where $T_{0}=273.15 \mathrm{~K}$ and $\mu_{0}=1.711 \cdot 10^{-5} \mathrm{~kg} /(\mathrm{ms})$.

\section{Numerical algorithm}

The numerical method is implemented in the computer solver FLUENT [4]. The solver is approached on the finite volume and on a cell centered discretization. Calculations 
are realized by blocks, each block being segregated in hexahedral cells. Discreditization of time is based on the second-order accurate Gear's formulation of the fully implicit scheme:

$\bar{\Omega}_{i j k} \frac{\frac{3}{2} \vec{W}_{i j k}^{n+1}-2 \vec{W}_{i j k}^{n}+\frac{1}{2} \vec{W}_{i j k}^{n-1}}{\Delta t}+\sum_{l=1}^{6}\left(\vec{F}_{c}-\vec{F}_{d}\right)_{i j k, l}^{n+1}=0$

\section{Boundary Conditions}

The numerical solid wall boundary conditions for cellcentered finite volume discetization procedures depend on the viscous and diffusive flux. More precisely, their computation needs the knowledge of the interface between primitive states and gradients.

Gradients are defined by the average over an ample control volume $\overline{\Omega_{i j k}}$ using the formulae of Green:

$$
(\nabla \Phi)_{i j k} \approx \frac{1}{\bar{\Omega}_{i j k}} \iint_{\partial \Omega_{i j k}} \Phi \vec{n}_{e x t} d S
$$

According to Ben Khelil [5], who has given two approximations, the first one uses staggered cells in order to evaluate the gradients at the cell interface and the second one computes the cell gradient at each cell center and affects an averaged value at the interface, while the use of a centered control volume method simplifies considerably the treatment of boundary conditions. Also, using this method leads to parasite oscillations due to a separation between even and odd points. For high speed flow configurations, this separation has no consequence.

Turbulent variables are particularly sensitive to this phenomenon; therefore, wall interfaces require some treatments:

The numerical properties of the Spalart-Allmaras model are that $\tilde{v}=k u_{\tau} y$ until the wall. A fictitious cell 0 can be used, (see Fig.3).

The cell 0 extrapolates the gradient associated with real cells 1,2 and 3 , therefore:

$$
\nabla 0=K_{1} \nabla_{1}+K_{2} \nabla_{2}+K_{3} \nabla_{3}
$$

where $K_{i}$ are the extrapolation coefficients. They can be chosen as a function of a desired degree of precision.

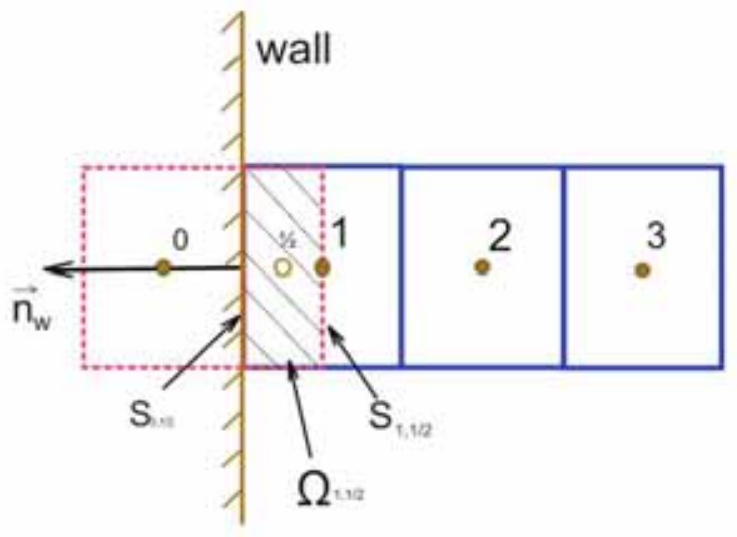

Figure 3. Real and fictitious cells of the wall

Pechier [3] proposed another technique of giving gradients to fictitious cells. The first real cell 1 is divided into two same cells. Gradients are evaluated in the nearest half cell from the wall, therefore:

$$
(\nabla \Phi)_{1,1 / 2} \approx \frac{1}{\bar{\Omega}_{1,1 / 2}}\left((\Phi \vec{S})_{0,1 / 2}+(\Phi \vec{S})_{1,1 / 2}\right)
$$

The velocity profile of a flat plate in supersonic free-stream conditions (see Fig.4) is presented during two different computational techniques for gradient calculation [2].

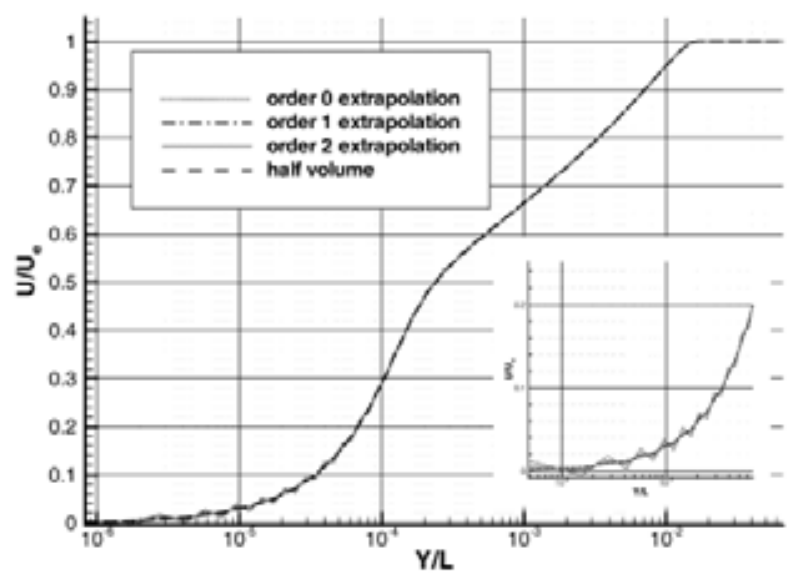

Figure 4. Influence of gradient calculation in fictitious cells [2]

One can note that a 0 order extrapolation results as it can be expected in parasite oscillations due to a separation between even and odd points and in no oscillation when using the half volume technique or the second order extrapolation. The second order gradient for turbulent variables shows to be a proper compromise between precision and robustness.

\section{Results and Discussion}

The Spalart-Allmaras model has been implemented in the FLUENT software and validated program [4]. Therefore, let us take a look at tests for generic configurations at $M=2$ and a moderate angle of attack (a simple ogive-cylinder body and an ogive-cylinder body-tail configurations).

The influence of $f_{v}$ functions is conducted for $\alpha=0$ degree. The flow is forced turbulent near the body nose and the Reynolds number based on the diameter is $1.2 \cdot 10^{6}$.

Let us see Fig.5,where the convergence history of the friction drag coefficient is presented. The modified functions $\left(f_{2}\right.$ and $\left.f_{3}\right)$ shift the laminar-to-turbulent transition backward and still do not modify the convergent value of the normal force coefficient. Furthermore, let us notice a slight difference of speed convergence.

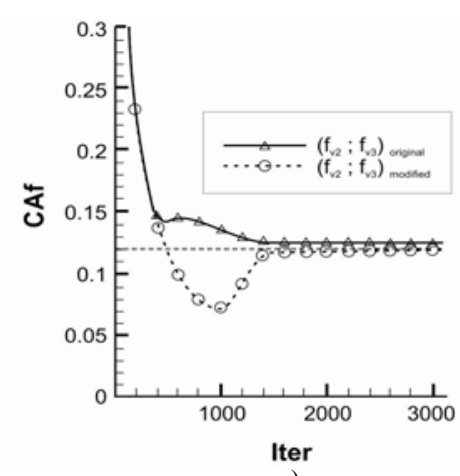

a)

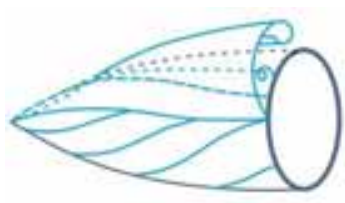

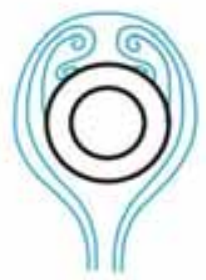

b)
Figure 5. a) Convergence history [6], b) Sketch of the flow field $\alpha=10 \mathrm{deg}$ 
An experimental study of an ogive-cylinder for $\alpha=10$ degrees, with oil flow visualizations, flow field figure, pressure distributions, boundary layer profiles, and skin friction values has been carried out at the ONERA, French wind tunnels, at $M=2$ [3]. The flow structure includes a primary vortex and a secondary one, Fig.5. This test demonstrated that the intensity of the vortex flow is sensitive to the laminar or turbulent nature of the boundary layers. First experiments were carried out with $R e=0.16 \cdot 10^{6}$, by [6]. This permitted to switch from the laminar to turbulent boundary layer when transition was free or triggered on the body apex.

Free stream conditions are $M=2$ and $\alpha=10$; laminar calculations are performed with $R e=0.16 \cdot 10^{6}$ and $R e=0.12 \cdot 10^{6}$ for all other turbulent calculations.

The grid has 400,000 points (61 in axial, 85 in radial and 73 in circumferential directions with $\Delta \Phi=2.5$ deg.). A normal size cell in the axial direction leading to $Y^{+}<1$ is assumed around the whole body.

The numerical validation is completed with the $\mathrm{K}$ epsilon model computation (Jones and Launder [7]).
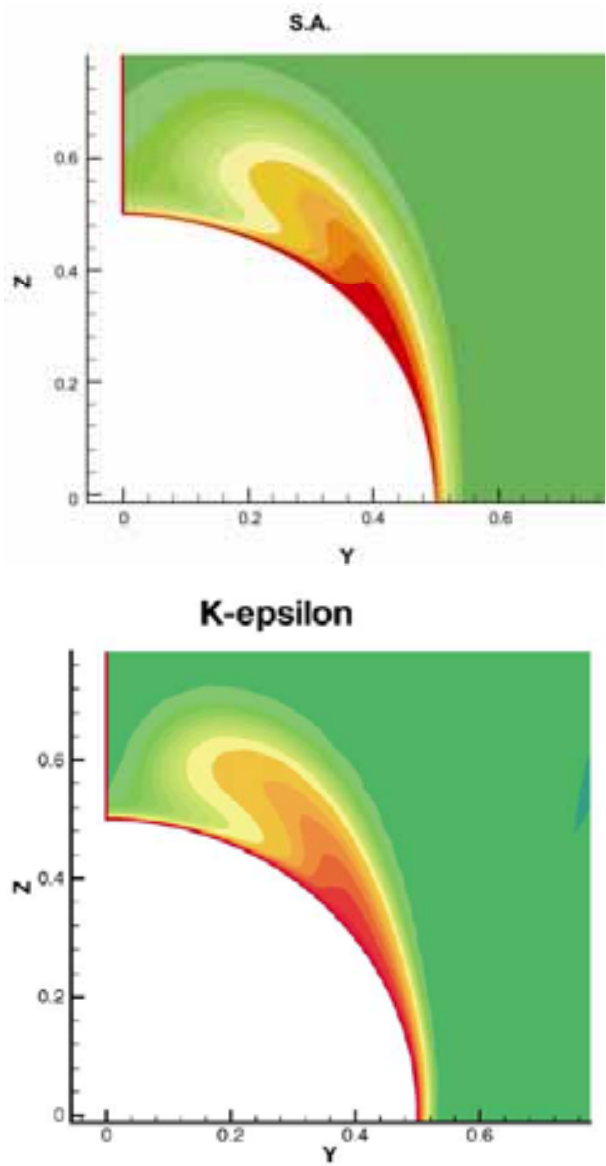

Figure 6. Total pressure $(p i / p i 0)$ contours in the cross section $X / D=7$ at $\alpha=10$ deg.

The computed skin friction lines are presented by a developed view in Fig.5. We can notice a good position of the primary separation line, observed in both models. The second separation line is sufficiently visible.

At the station $X / D=7$, the main vortex on the upper side of the body, see Fig.6, is developed, while the secondary vortex is built-in in the boundary layer, and therefore cannot be clearly seen. The computational results are sensitive to viscous effects and turbulent modeling. Moreover, the Spalart-Allmaras model and the K-epsilon give very close results for total pressure and eddy viscosity, see Fig.7.
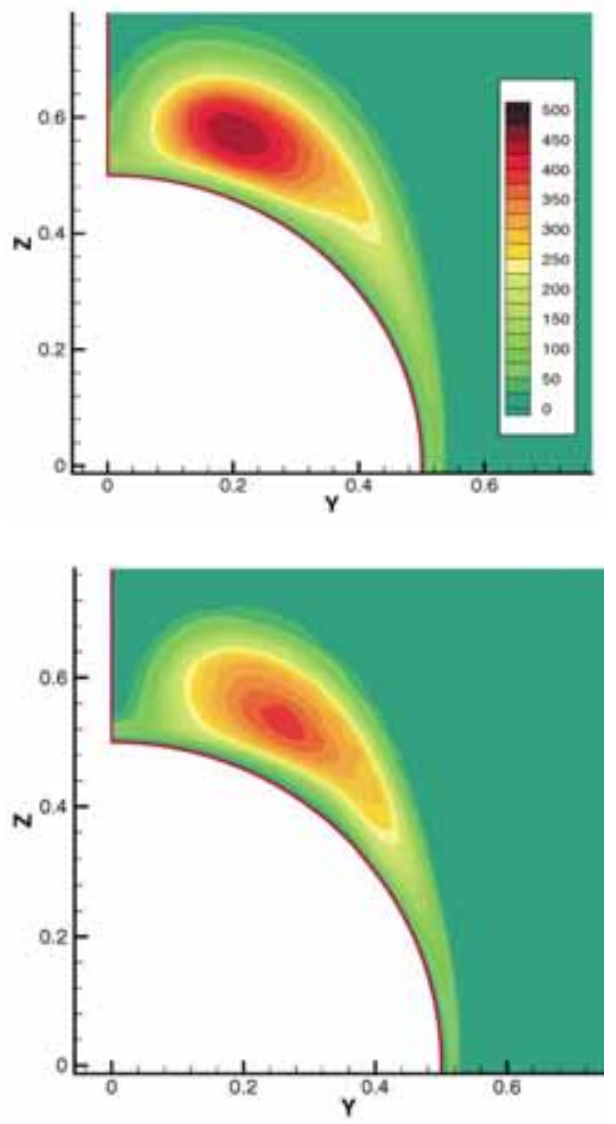

Figure 7. Eddy viscosity field (Spalart-Allmaras and K-eps).

The cumulated normal force coefficient calculated by the integration of pressure distributions along the body is presented in Fig.9. Both models give the same normal force coefficients.

The second test case is in order to get an insight into the effect of vortices on the overall aerodynamics of a body-tail configuration. The Spalart-Allmaras model solutions are computed for $M=2$ and $\alpha=22.5^{\circ}$ steady flow. Fig.8 shows the fore-body vortices acting on the fins.

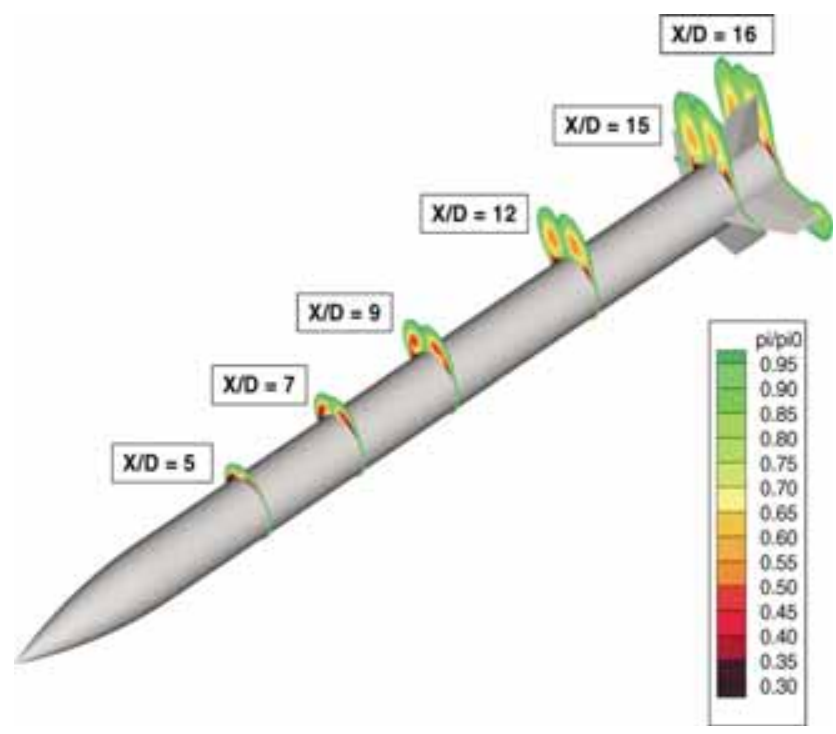

Figure 8. Total pressure contours.

If the results are compared to the Euler solutions for the prediction of the normal force, Fig.9, it can be noticed that they are similar. 


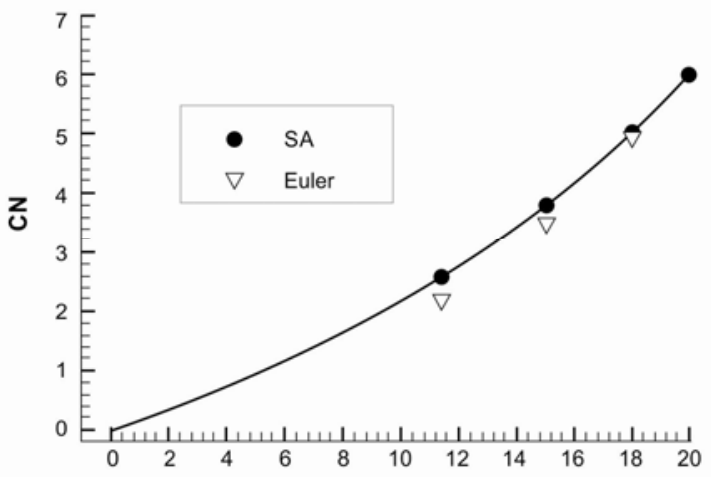

Figure 9. Normal force coefficient.

This reality can be explained by the fact that, with an inviscid solution the body lift is underestimated, whereas the fin lift is overestimated, without or with a very small effect of the vortices.

According to S. Deck [3], generic configurations have been studied for supersonic flows and moderate angles of attack, body alone and body-tail. For body alone, none of the models is really satisfactory - the Spalart-Almaras model and the K-epsilon model give very close results, but remotely overestimate the eddy viscosity. The $C_{N}$ induced by the vertical flow has no tangible effect on the global longitudinal characteristics.

\section{Conclusion}

The Spalart-Allmaras turbulence model has been developed and designed for subsonic flows around airfoils, additionally to subsonic and transonic flows around aircraft configurations.

An annex of its formulation to compressible flows and its application to three dimensional supersonic flows have been achieved. A greater care has to be taken relating to the definition of the model damping functions and discretization of viscous gradients near boundary layers. The usefulness of this model for supersonic flows is the ability to compute the ogive leeward side vortices as an influence for the evaluation of external flows.

The main conclusion is that the Spalart-Allmaras model does a good job near wake where the vorticity is domination strain rate, which means that the SpalartAllmaras model takes a good care of the overproduction of eddy viscosity.

In comparison with the K-epsilon model, the SpalartAllmaras model gives the same results, but the dissipation rate is much faster than with the Spalart-Allmaras model.

The characteristics of the Spalart-Allmaras model in studying flow conditions can be seen in this work. On the other hand, unsteady flows bring time $(t)$ as a momentous variable. Therefore, future work will extend the domain of its application to unsteady flows.

\section{References}

[1] DENIAU,H.: Calcul d'écoulements super-soniques pou résolution des équations de Navier-Stokes parabolisées: ModéliSpalartAllmaras tion de la Turbulence.Traitement des poches subsoniques, PhD thesis, ENSPALART-ALLMARAS E, 1996.

[2] JAVAHERCHI,T.: Review of Spalart-Allmaras Turbulence Model, 2010.

[3] DECK,S., DUVEAU,P., D'ESPINEY,P., GUILLEN,P.: Development and application of Spalart-Allmaras one equation turbulence model to three-dimensional supersonic complex configurations. Aerospace Science and Technology, 2002, 6, pp.171-183.

[4] www.fluentusers.com

[5] BEN KHELIL,S.: Simulation numérique d'écoulements turbulents autour de configurations complexes. Application au roulis induit des missiles, PhD thesis, Université de Paris 13, 1998.

[6] PAGAN,D., MOLTON,P., DELERY,J.: Basic experiment on a supersonic vortex flow around a missile a missile body, AIAA J. Spacecraft Rockets, 1992, Vol.29, No.3, pp.373-378.

[7] JONES,W.P., LAUNDER,B.E.: The prediction of laminarization with a 2-equation model of turbulence, Internat. J. Heat Mass Transfer 15.

[8] SPALART,P.R., ALLMARAS,S.R.: $A$ one equation turbulence model for aerodynamic flows, AIAA Paper 92-0439, 1992.

[9] SPALART,P.R., ALLMARAS,S.R.: A one equation turbulence model for aerodynamic flows, in: La Recherche Aérospatiale, 1994, No 1, pp. 5-21.

[10] TEWARI,A.: Atmospheric and Space Flight Dynamics, 2007 Birkhauser Boston

[11] ČANTRAK S.: Mehanika Fluida, teorija i praksa.Univerzitet u Beogradu 2005.ISBN 86-7083-523-1

\section{Prikaz Spalart-Almaras turbulentnog modela i njegovih modifikacija za trodimenzionalne nadzvučne konfiguracije}




\title{
Показ турбулентной модели Spalart-Allmaras и её модификаций для трёхмерных сверхзвуковых конфигураций
}

\begin{abstract}
Spalart-Allmaras есть турбулентная модель для моделирования различных типов турбулентного потока и особенно пользуется в аэродинамике. Ещё с 1992 года, когда её публиковали Spalart и Allmaras, модифицированы разные части основного уравнения (предусмотрение, диффузия и разрушение). В настоящей статье обрабатывается основное уравнение модели и объясняется роль каждой части этого уравнения. Модель использована в трёхмерных сжимающихся сверхзвуковых потоках и опробована на двух различных кофигурациях. Во-первых, симуляция баллистического снаряда, а потом и ракеты с оперениями в форме креста указывают на возможность и способность настоящей модели применить взаимодействие фюзеляжа и руля направления.
\end{abstract}

Ключевые слова: аэродинамика, вычислительная гидродинамика, моделирование процессов, турбулентный поток, сверхзвуковой поток, численное моделирование, аэродинамика снаряд.

\section{Présentation du modèle de turbulence Spalart-Almaras et de ses modifications pour les configurations supersoniques à trois dimensions}

\begin{abstract}
Spalart-Almaras est un modèle de turbulence pour la modélisation de différents types d'écoulements turbulents utilisé spécialement dans l'aérodynamique. Depuis 1992 quand il a été publié de la part de Spalart et Almara Spalart 6Almaras on a modifié différents partie de l'équation principale (prévision, diffusion et destruction ). Dans ce papier on considère la principale équation du modèle et on explique le rôle de chacune de ses parties. Le modèle est mis en ouvre dans l'écoulement compressible à trois dimensions supersoniques et testé pour deux différentes configurations. D'abord la simulation du missile balistique, ensuite du missile à ailette en croix démontrent la capacité de ce modèle d'utiliser l'interaction entre le fuselage de l'aéronef et de ses ailettes.
\end{abstract}

Mots clés: aérodynamique, dynamique numérique des fluides, modélisation du processus, écoulement turbulent, écoulement supersonique, simulation numérique, aérodynamique des projectiles 